\title{
L-BAND RADIOMETER CALIBRATION CONSISTENCY ASSESSMENT FOR THE SMOS, SMAP AND AQUARIUS INSTRUMENTS
}

\author{
Emmanuel Dinnat ${ }^{1,2}$, David Le Vine ${ }^{1}$ \\ ${ }^{1}$ Cryospheric Sciences Laboratory, NASA Goddard Space Flight Center, Greenbelt MD, U.S.A. \\ ${ }^{2}$ CEESMO, Chapman University, Orange, CA, U.S.A.
}

\begin{abstract}
Three L-band radiometers have been observing the Earth in order to retrieve soil moisture and ocean salinity. They use different instrument configurations and calibration and retrieval algorithms. In any case, the brightness temperature retrieved at the Earth surface should be consistent between all instruments. One reason for inconsistency would be the use of different approaches for the instrument calibration or the use of different models to retrieve surface brightness temperature. We report on the different approaches used for the SMOS, SMAP and Aquarius instruments and their impact on the observations consistency.
\end{abstract}

Index Terms - L-band, calibration, passive microwave, SMOS, SMAP, Aquarius

\section{INTRODUCTION}

Observations at L-band (measurements in the spectral window around $1.413 \mathrm{GHz}$ set aside for passive use only) are particularly well suited to measuring soil moisture and sea surface salinity from space. The sensitivity of thermal emission from ocean water to changes in salt content peaks near this window and decays very rapidly with increase in frequency. The response of soil to changes in water content is also strong in this frequency band and the frequency is sufficiently low to permit penetration through modest vegetation canopy. The longer wavelength permits deeper penetration into the vegetation canopy and also into the soil, increasing the sensitivity to soil moisture over more varied landscape than at higher frequencies for which vegetation quickly becomes opaque. New applications are also developing and recent research suggests that the large penetration depth of L-band can be used to retrieve the thickness of thin sea ice [1] and some snow properties [2;3].

There is now data from three L-band Earth remote sensing missions in space, SMOS, Aquarius and SMAP. The SMOS mission was first, launched by the European Space Agency (ESA) in 2009 [4]. Aquarius followed in 2011 with the launch of Aquarius/SAC-D [5; 6]. The recent launch in 2015 of the Soil Moisture Active/Passive (SMAP) mission by NASA [7] completed the triumvirate. The
Aquarius/SAC-D observatory was lost in June, 2015; however, it collected nearly 4 years of quality data overlapping both SMOS and SMAP, and the data is continuing to be process and refined (the Aquarius mission will officially end in June, 2017). Ideally, it would be possible to combine the data from these three missions to obtain enhanced science products. But, each mission was designed with different main objectives (e.g. Aquarius was focused on retrieving sea surface salinity and SMAP was focused on retrieving soil moisture) and this resulted in differences in the sensors which complicates intercomparison and combining of the data.

In this presentation we will report on the consistency of the calibration between the SMOS, SMAP and Aquarius sensors. We will assess the differences in the models used for their calibration and the retrieval of surface brightness temperature. We will report on approaches to allow for comparison of TB despite difference in observation geometry (e.g. incidence angle).

\section{DIFFERENCES IN FORWARD MODEL}

We report on the differences between the forward model and ancillary data used by the three missions. The forward model is used in the calibration process of the measured antenna temperatures (TA) or to correct for various effects (e.g., reflected galaxy, atmospheric effects) to transform the measured TA into the surface TB. SMAP and Aquarius use comparisons between measured TA and simulated TA (so called 'expected' TA) to correct for average global bias and its temporal drift [8;9]. The calibration is also assessed using monthly observation of the celestial sky [10] which is an independent scene and uses a simpler model for expected TA (e.g., negligible atmospheric effects between the Sky and the instrument). For SMOS, the level 1 uses only the cold sky for its calibration. However, the bias and temporal drift are then evaluated using a forward model for the Earth emission (oceans). Namely, its calibration is not directly adjusted based on the comparisons with the forward model, but the model is used as a metric of the calibration performance $[11 ; 12]$. In addition, the SMOS level 2 product for oceans directly uses the forward model to adjust the TB calibration before the retrieval of SSS is applied, applying a 
so-called Ocean Target Transformation (OTT) [13; 14]. Therefore, the details of the forward model used by each mission are a critical part of ensuring consistency in the calibration between the various sensors. Among the issues to be addressed regarding the use of the forward model, are the differences in ocean surface roughness, dielectric constant, sea surface temperature, reflected galaxy, land and sea ice contributions, and atmospheric corrections (including Faraday rotation).

\section{EXAMPLES OF TB COMPARISONS}

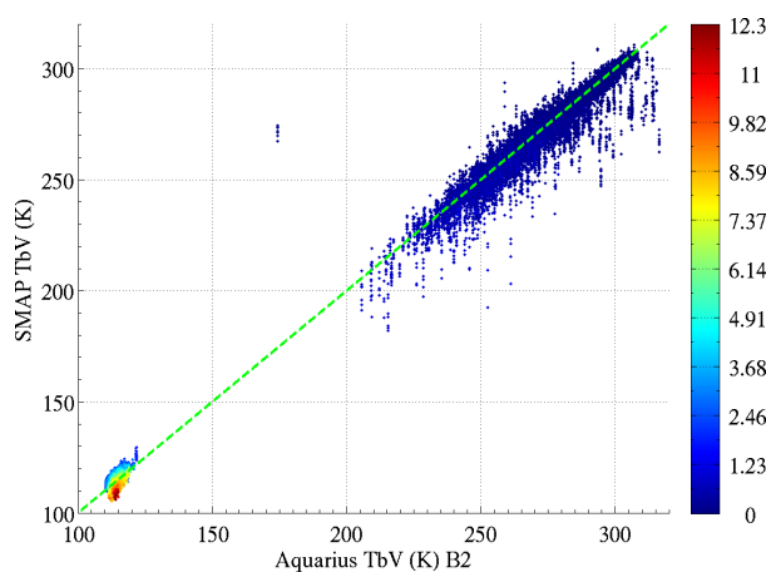

Fig. 1 Comparison of SMAP and Aquarius surface TB in vertical polarization. SMAP TB are reported as a function of collocated Aquarius TB (middle beam) with colors reporting the reflected galaxy correction on the SMAP data in Kelvin.

Fig. 1 shows a comparison of TB measured by SMAP and Aquarius (middle beam only) collocated over oceans and land. The collocations for a one week period (from May 15, 2015) use a distance radius of $20 \mathrm{~km}$ around Aquarius observations and a time windows of 40 minutes. Only observations with at least $99 \%$ of land (TB $>200 \mathrm{~K}$ ) or at least $99.9 \%$ of ocean $(\mathrm{TB}<130 \mathrm{~K})$ in the field of view are reported. The color scale reports the correction in Kelvin for the galaxy reflection applied to SMAP TA observations as part of the process of retrieving surface TB. Aquarius middle beam is used because of its proximity in incidence angle $\left(38.5^{\circ}\right)$ to SMAP observations $\left(40^{\circ}\right)$. Over land (middle and top right corner) TB are close between both instruments with an average difference of the order of $1 \mathrm{~K}$ only. Over ocean (lower left corner) the match between SMAP and Aquarius is very dependent on the amount of correction for the reflected galaxy correction. This shows that the reflected galaxy is a source of uncertainty that needs to have a consistent correction between all missions.

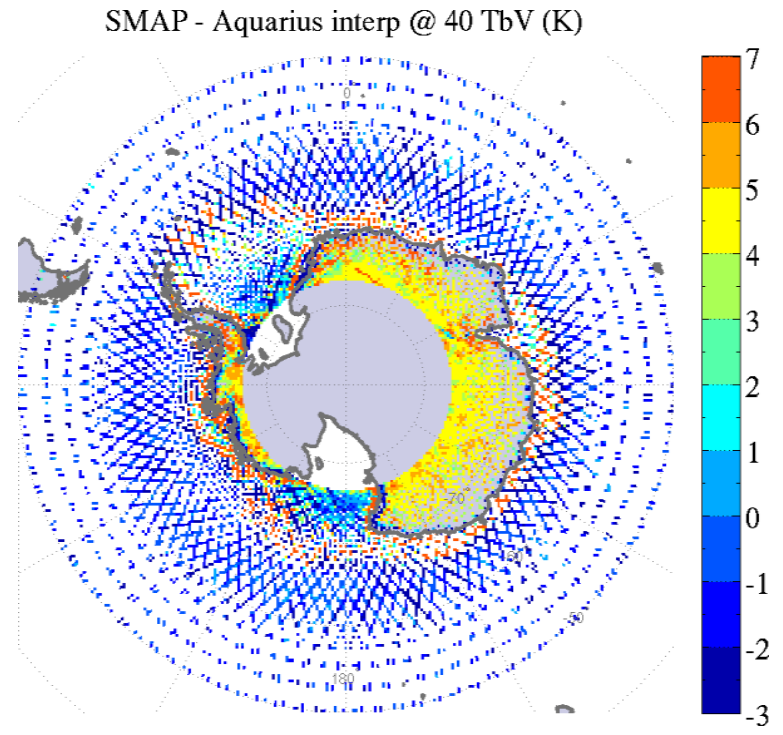

Fig. 2 TB difference between SMAP and Aquarius (interpolated at $40^{\circ}$ incidence angle) averaged over one week in May 2015 over Antarctica.

Fig. 2 shows the comparison of brightness temperatures over Antarctica. (Note: differences reported over the ocean are not meaningful because they are not collocated in time, which is an issue over ocean because of fast changing TB, contrary to Antarctica where TB at L-band is very stable, [15]). Aquarius observations were interpolated to an incidence angle of $40^{\circ}$ to match SMAP by using collocated observation from Aquarius middle $\left(38.5^{\circ}\right)$ and outer beam $\left(46.8^{\circ}\right)$. The correction for incidence angle difference is small $(\sim 0.5 \mathrm{~K})$ because TB is slowly varying with incidence angle in this range, and the incidence angle difference is small. In this comparison, the average difference between SMAP and Aquarius TB over Antarctica is of the order of 4 $\mathrm{K}-5 \mathrm{~K}$, which is larger than the difference observed over land $(1 \mathrm{~K})$. The difference between land and Antarctica can be traced to differences in the atmospheric model used to compute surface TB from the observed TA. This is shown in Fig. 3. The atmospheric correction is similar between SMAP and Aquarius over most of the globe, but differs significantly $(\triangle \mathrm{TB} \sim 3.5 \mathrm{~K})$ over Greenland and Antarctica. This is an illustration that difference in models and ancillary data used in the retrievals can impact the calibration and inter-comparison of surface TB. 


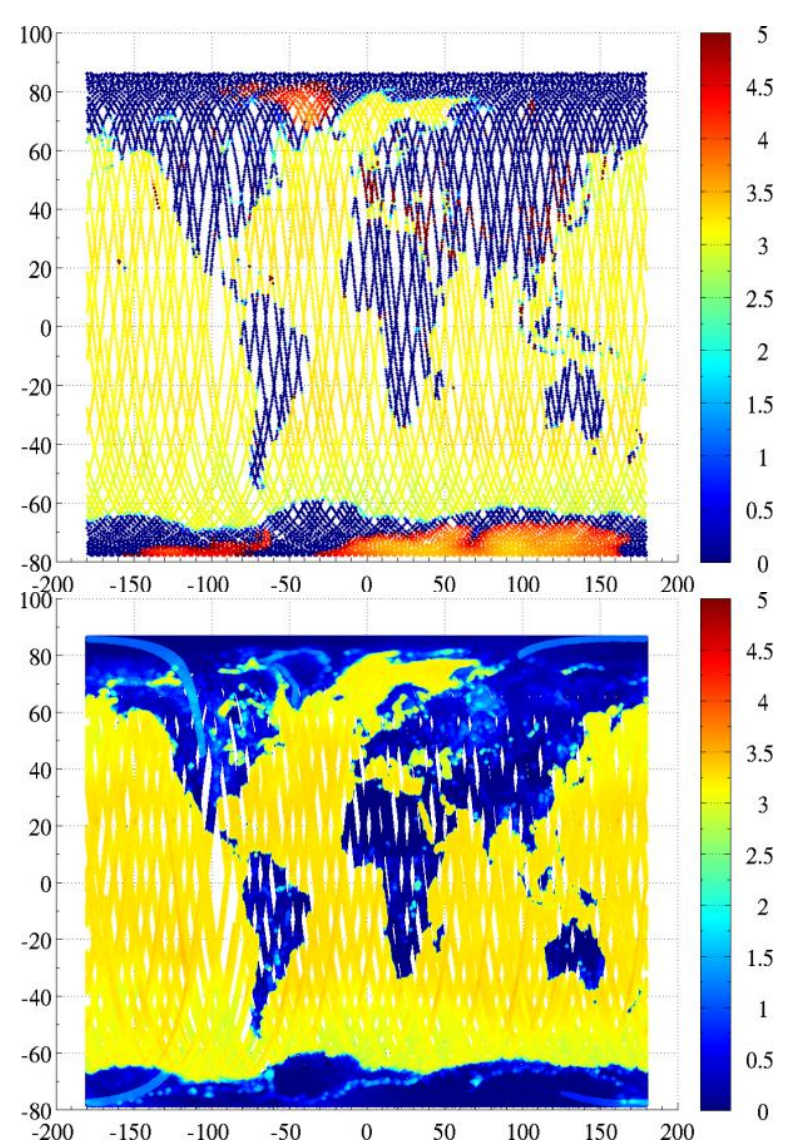

Fig. 3 Atmospheric correction applied to observed TA to compute TB for (top) Aquarius and (bottom) SMAP. The correction differs significantly $(\triangle \mathrm{TB} \sim 3.5 \mathrm{~K})$ over Antarctica and Greenland.

\section{CONCLUSIONS}

We report on the differences in models and ancillary data used by SMOS, SMAP and Aquarius missions, and assess their impact on the surface TB inter-consistency between the three L-band radiometers.

\section{REFERENCES}

[1] X. Tian-Kunze, L. Kaleschke, N. Maaß, M. Mäkynen, N. Serra, M. Drusch, and T. Krumpen, "SMOS-derived thin sea ice thickness: algorithm baseline, product specifications and initial verification," The Cryosphere, vol. 8, no. 3, pp. 997-1018, 2014. [2] L. Brucker, E. P. Dinnat, G. Picard, and N. Champollion, "Effect of snow surface metamorphism on Aquarius L-band radiometer observations at Dome C, Antarctica," IEEE Trans. Geosci. Remote Sensing, vol. 52, no. 11, pp. 7408-7417, Nov 2014.

[3] M. Schwank, et al., "Snow density and ground permittivity retrieved from L-Band radiometry: A synthetic analysis," Selected Topics in Applied Earth Observations and Remote Sensing, IEEE Journal of, vol. 8, no. 8, pp. 3833-3845, Aug 2015.
[4] Y. H. Kerr, et al., "The SMOS mission: New tool for monitoring key elements of the global water cycle," Proceedings of the IEEE, vol. 98, no. 5, pp. 666-687, May 2010.

[5] G. Lagerloef, et al., "The Aquarius/SAC-D mission designed to meet the salinity remote sensing challenge," Oceanography Magazine, vol. 21, no. 1, pp. 68-81, March 2008.

[6] D. M. Le Vine, G. S. E. Lagerloef, and S. E. Torrusio, "Aquarius and remote sensing of sea surface salinity from space," Proceedings of the IEEE, vol. 98, no. 5, pp. 688-703, May 2010.

[7] D. Entekhabi, et al., "The Soil Moisture Active Passive (SMAP) mission," Proceedings of the IEEE, vol. 98, no. 5, pp. 704-716, May 2010.

[8] J. Piepmeier, S. Brown, J. Gales, L. Hong, G. Lagerloef, D. Le Vine, P. de Matthaeis, T. Meissner, R. Bindlish, T. Jackson, and E. Dinnat, "Aquarius radiometer post-launch calibration for product version 2," NASA, Tech. Rep. AQ-014-PS-0015, 2013.

[9] D. M. Le Vine, E. P. Dinnat, S. Abraham, P. de Matthaeis, and F. J. Wentz, "The Aquarius simulator and cold-sky calibration," IEEE Trans. Geosci. Remote Sensing, vol. 49, no. 9, pp. 31983210, September 2011.

[10] Dinnat, E. P., D. M. Le Vine, J. R. Piepmeier, S. T. Brown, and L. Hong. "Aquarius L-band Radiometers Calibration Using Cold Sky Observations." IEEE J. Sel. Top. Appl. Earth Observations Remote Sensing, .2015.

[11] X. Yin, J. Boutin, and P. Spurgeon, "First assessment of SMOS data over open ocean: Part I - Pacific Ocean," IEEE Trans. Geosci. Remote Sensing, vol. 50, no. 5, pp. 1648-1661, May 2012.

[12] L. Wu, F. Torres, I. Corbella, N. Duffo, I. Duran, M. Vallllossera, A. Camps, S. Delwart, and M. Martin-Neira, "Radiometric performance of smos full polarimetric imaging," Geoscience and Remote Sensing Letters, IEEE, vol. 10, no. 6, pp. 1454-1458, Nov 2013.

[13] J. Gourrion, R. Sabia, M. Portabella, J. Tenerelli, S. Guimbard, and A. Camps, "Characterization of the SMOS instrumental error pattern correction over the ocean," Geoscience and Remote Sensing Letters, IEEE, vol. 9, no. 4, pp. 793-797, 2012.

[14] J. Font, et al., "SMOS first data analysis for sea surface salinity determination," International Journal of Remote Sensing, vol. 34, no. 9-10, pp. 3654-3670, 2013.

[15] L. Brucker, E. P. Dinnat, and L. Koenig, "Weekly-gridded Aquarius L-band radiometer/scatterometer observations and salinity retrievals over the polar regions - Part 2: Initial product analysis," The Cryosphere, vol. 8, no. 3, pp. 915-930, 2014a. 